\title{
THE USE OF SATELLITE IMAGERY TO GUIDE FIELD PLOT SAMPLING SCHEME FOR BIOMASS ESTIMATION IN GHANAIAN FOREST
}

\author{
B. P. Sah ${ }^{\text {a }}$, J. M. Hämäläinen ${ }^{\text {b }}$, A. K. Sah ${ }^{\text {a }}$, K. Honji ${ }^{\text {a }}$, E. G Foli ${ }^{\text {c }}$ C. Awudi ${ }^{\text {d }}$,

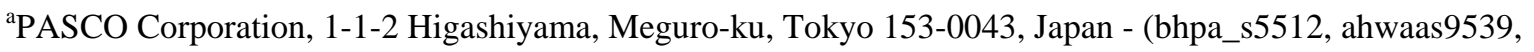 \\ kiojin6937)@pasco.co.jp \\ boy Arbonaut Ltd., Latokartanontie 7 A , FIN-00700 Helsinki, Finland - jarno.hamalainen@arbonaut.com \\ 'Forestry Research Institute of Ghana, University PO Box 63, Kumasi, Ghana - efoli@csir-forig.org.gh \\ ${ }^{\mathrm{d}}$ The Forestry Commission of Ghana, P.O. Box MB 434, West Legon, Accra, Ghana - cawudi@hq.fcghana.com
}

Commission IV, WG IV/8

KEY WORDS: LiDAR, Estimation, Land Use, Sampling Strips, Satellite Imagery, Biomass

\begin{abstract}
:
Accurate and reliable estimation of biomass in tropical forest has been a challenging task because a large proportion of forests are difficult to access or inaccessible. So, for effective implementation of REDD+ and fair benefit sharing, the proper designing of field plot sampling schemes plays a significant role in achieving robust biomass estimation. The existing forest inventory protocols using various field plot sampling schemes, including FAO's regular grid concept of sampling for land cover inventory at national level, are time and human resource intensive. Wall to wall LiDAR scanning is, however, a better approach to assess biomass with high precision and spatial resolution even though this approach suffers from high costs.

Considering the above, in this study a sampling design based on a LiDAR strips sampling scheme has been devised for Ghanaian forests to support field plot sampling. Using Top-of-Atmosphere (TOA) reflectance value of satellite data, Land Use classification was carried out in accordance with IPCC definitions and the resulting classes were further stratified, incorporating existing GIS data of ecological zones in the study area. Employing this result, LiDAR sampling strips were allocated using systematic sampling techniques. The resulting LiDAR strips represented all forest categories, as well as other Land Use classes, with their distribution adequately representing the areal share of each category. In this way, out of at total area of $15,153 \mathrm{~km}^{2}$ of the study area, LiDAR scanning was required for only $770 \mathrm{~km}^{2}$ (sampling intensity being $5.1 \%$ ). We conclude that this systematic LiDAR sampling design is likely to adequately cover variation in above-ground biomass densities and serve as sufficient a-priori data, together with the Land Use classification produced, for designing efficient field plot sampling over the seven ecological zones.
\end{abstract}

\section{INTRODUCTION}

In the light of recent global climate changes, issues relating to Reducing Emissions from Deforestation and forest Degradation (REDD, or REDD+) in developing countries have become critical because changes in land use and land cover pattern have significant impacts on the amount of greenhouse gas emissions, biodiversity, biogeochemical and hydrological cycles. In order to monitor emission reductions from deforestation and forest degradation, countries need to establish Reference Levels (RLs) and carbon accounting systems (Angelsen, et al, 2011a;b) with required standards for harnessing REDD+ benefits. Furthermore, the international community has increasingly realised the significant role of forest conservation and sustainable forest management that involves and respects the livelihoods and land use rights of indigenous people / local communities (Larson, 2011), and the enhancement of forest carbon stocks in developing countries as an important measure to mitigate global climate change.

Forestry in Ghana is playing an important environmental role including biodiversity, ecosystem services, maintaining river flow and natural water bodies, and other related issues at regional level (MEST, 2002). The total land area of Ghana is $238,000 \mathrm{~km}^{2}$ and according to the FAO forest definition the area of forest is estimated to be $49,400 \mathrm{~km}^{2}$ (FAO, 2010) of which $3,950 \mathrm{~km}^{2}$ is classified as primary forest that is amongst the most diverse ecosystems on the planet. Deforestation rate in Ghana was approximately $1.9 \%$ per annum in the period 1990 to 2005 and this rate is thought to have increased in the period 2005-2010 to about 2.1\%. The current rate of deforestation in Ghana clearly shows the need for devising forest management and conservation plans that includes a REDD+ mechanism. Furthermore, Ghana has a number of legislative instruments that guide the management and utilization of the nation's forest and wildlife resources, under the auspices of the Forestry Commission (FC) of Ghana (GOG, 1992; MLF, 1994; MLF, 1999), since the national forest policy seeks to ensure the sustainable utilization and development of the natural resources. Currently the FC is building its technical capabilities for mapping, monitoring and forest inventory to assess land use/land cover change and estimation of biomass with known accuracy to realise the twin goal mentioned above.

Previous large-scale forest inventories in Ghana have been based, primarily, on field data collection campaigns, which typically are time and human resource intensive activities. For example under the FC's Forest Inventory Project during 198588 and FAO's Forest Reserve Inventory Project during 1980-83 (Wong, 1989), the inventory covered only the south-

\footnotetext{
* Corresponding author.
} 
westernpart of Ghana. Recently, under the national level forest assessment program, FAO is mostly using the field plot sampling technique, employing $1 \mathrm{~km} \times 1 \mathrm{~km}$ systematic grid based sampling location, for forest inventory, e.g., Bangladesh National Forest and Tree Resources Assessment project conducted during 2005-2007 (Altrell et al, 2007).

Satellite Remote Sensing is a primary information source for Land Use and Land Cover and forest assessment as it provides images of wider areas in a relatively faster and more costefficient manner anywhere in the world. Since the 1970s, after the launch of Landsat Earth Observation Satellite, several satellites (with both optical and SAR sensors) have been launched and the trend is continuing at present, with several others planned to be launched in future; with time, spatial resolution has also improved to a large extent. Recent high resolution satellites, such as ALOS (Advanced Land Observing Satellite) and AVNIR-2 (Advanced Visible and Near Infrared Radiometer type 2), imagery can be used for analysis of present forest cover status (Nonomura et al, 2010; Soyama et al, 2010). AVNIR-2 imagery can be conveniently used for the six IPCC Land Use (LU) categories (Bickel et al, 2006) classification followed by further categorization of land cover refined by other criteria, such as ecological zone.

Though there have been major advances in satellite remote sensing technologies during the last decade, it remains difficult to detect forests with high above-ground biomass concentrations and changes due to degradation by relying on them. Airborne LiDAR (Light Detection-and-Ranging) sensors emit laser pulses that penetrate even through a dense multilayered canopy and the return pulses backscattering from vegetation and ground can be used to measure canopy height and density very accurately. There is a strong statistical correlation between the spatial distribution of return pulses and aboveground biomass. LiDAR-based modeling results in average biomass estimation Root Mean Square Error (RMSE) of better than $15 \%$ for a hectare land unit.

Although wall to wall LiDAR scanning gives high accuracy it comes with high cost and is therefore not feasible at large scale project level, once the resource value remains low and enhanced precision does not compensate the cost of data procurement. The LiDAR-Assisted Multisource Programmes (LAMP) for carbon stock assessments usually rely on a 5-10\% LiDAR transect sample, field plot measurements and wall-towall satellite datasets over the project area. Implementation of a LAMP approach helps to lower necessary field sampling intensity and LiDAR data provides a prior information basis for objective and efficient field plot sampling. Besides it allows generation of numerous extra biomass sample plots, referred to as surrogate sample plots, by means of regression models that rely on LiDAR metrics (Gautam et al, 2010) for different broad forest types.

The objective of this study is to demonstrate how LiDAR sampling transects can be validated by using detailed LU classification derived with wall to wall high resolution satellite imagery and secondary source GIS data in Ghanaian high forest zones.

\section{STUDY AREA AND DATA}

\subsection{Study Area}

The study area $\left(15,153 \mathrm{~km}^{2}\right)$ is located in the western border of Ghana, spanning the Western, Ashanti and Brong Ahafo Regions, as shown in Figure 1. The study area was selected with due consideration for the inclusion of all dominant ecological zones in the high forest zone of the country, thus representing all major forest types for formulating representative biomass estimation models at national level.

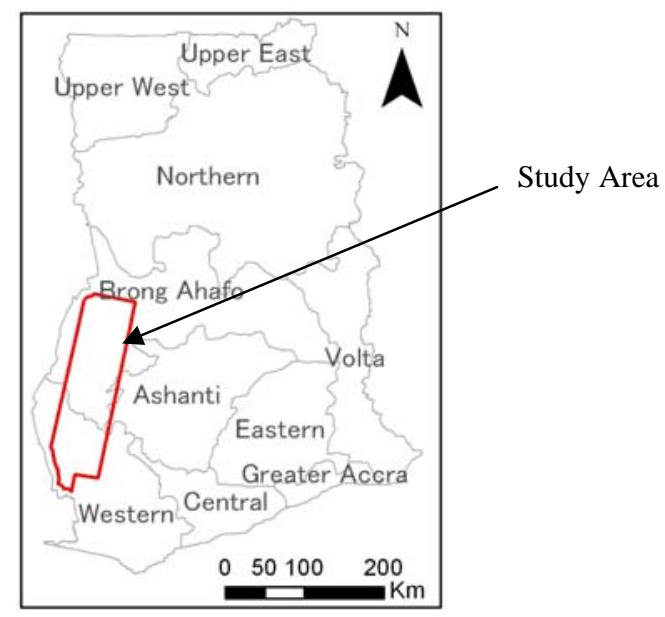

Figure 1. Map of Ghana Showing the Study Area, which Covers the Brong Ahafo, Ashanti and Western Regions and Includes all Major Ecological Zones

\subsection{Satellite Data}

ALOS AVNIR-2 satellite data (spatial resolution 10m) were used to extract latest LU classification in this study. The areas where AVNIR-2 data were lacking or covered by clouds were complemented by a scene of Disaster Monitoring Constellation (DMC) satellite data with $22 \mathrm{~m}$ resolution. The AVNIR-2 is one of three sensors equipped in ALOS and collects data in 4 bands: Blue, Green, Red, and Near Infra-Red. DMC satellite data has 3 bands; Green, Red, and Near Infra-red. In this study, seven AVNIR-2 scenes with acquisition date between 28th January, 2010 and 2nd January, 2011 and one DMC with acquisition date 19th January, 2011 were used.

\subsection{Secondary Source GIS Data}

In order to further stratify the LU classification from satellite data, GIS data of ecological zones were used. According to Hall and Swaine, 1981, there are 10 broad ecological zones in Ghana and seven (7) of them occur within the study area with prevalent high forests. The forest types, based on the ecological zoning, are as follows:

1) Savannah (S)

2) Dry semi-deciduous (fire zone) (DSD-F)

3) Dry semi-deciduous (inner zone) (DSD-I)

4) Moist semi-deciduous (north west subtype) (MSD-NW)

5) Moist semi-deciduous (south east subtype) (MSD-SE)

6) Moist evergreen (ME)

7) Wet evergreen (WE) 
The forest types remaining outside are upland evergreen, southern marginal and mangrove forests.

\section{METHODOLOGY}

The general workflow of this study is presented in Figure 2. In brief, after carrying out pre-processing, such as orthorectification (to the target coordinate system UTM, WGS84, Zone $30 \mathrm{~N}$ ), LU classification was performed, which was further stratified by incorporating existing GIS data of the ecological zone. Then, the final LU result was used in designing LiDAR sampling strips.

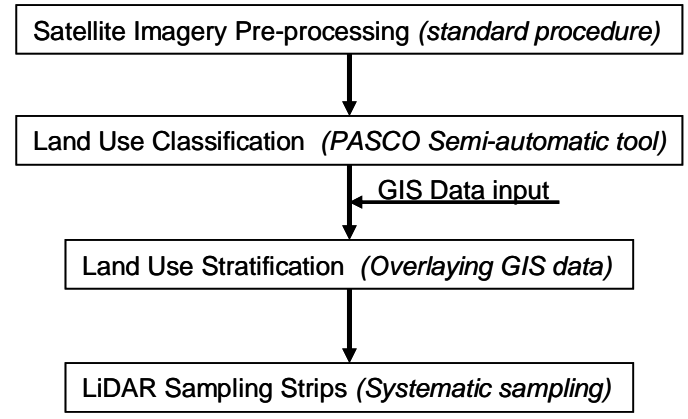

Figure 2. General Workflow

\subsection{Land Use Classification and Stratification}

With respect to LU classes, all the six principal IPCC LU classes were included, namely: Forest Land, Cropland, Grassland, Settlements, Wetlands, and Other Land. As per IPCC definition, Forest Land includes all land with woody vegetation consistent with thresholds used to define Forest Land in the national greenhouse gas inventory. It also includes systems with a vegetation structure that currently fall below, but in situ could potentially reach the threshold values used by a country to define the Forest Land (Bickel et al, 2006). In addition, two sub-categories of forest canopy cover used by the Forestry Commission of Ghana, i.e., Forest Land (Closed canopy $>60 \%$ ), and Forest Land (Open canopy < 60\%), were considered. Thus, altogether seven (7) LU classes were included in the LU classification.

The LU classification was carried out using PASCO Tool ${ }^{\mathrm{TM}}$ employing all 4 bands of ALOS AVNIR-2 and 3 bands of DMC. The major steps employed were:

- Conversion of DN to Top-of-Atmosphere (TOA) reflectance.

- Estimation of Normalised Difference Vegetation Index (NDVI).

- Slicing the image using NDVI threshold and band 3 TOA reflectance to know the gross area for vegetation and nonvegetation.

- Masking satellite image with above mask area and then running "Unsupervised classification" for 20 classes.

- Recoding the resultant classes to the appropriate one of 7 LU classes considering the ground truth data and then compiling them together.

- Lastly, carrying out the manual editing.

The above methodology required less manual editing (Sah et al, 2010). The resulting classified data were further stratified by overlaying the GIS data of the ecological zones.

\subsection{Validating LiDAR Sampling Design}

As a preliminary step the final LU classification product was resampled from $10 \mathrm{~m}$ to $100 \mathrm{~m}$ pixel resolution by applying a majority rule. This was mainly due to the field observation protocol for 55 independent ground spots visited over different LU types and all the ecological zones. Land use, basal area, diameter at breast height $(1.3 \mathrm{~m})$ of the basal area median tree and height of the basal area median tree were recorded from the centre of each spot. Additionally, 4 forest view photos and 5 canopy view photos were taken $10 \mathrm{~m}$ apart from the centre towards cardinal points (North, East, South and West).

The resampled classification data were inputted for validating the systematic LiDAR strips sampling design. In this study, 'Pearson's chi-squared test' has been applied to assess the sampling representativeness of Forest Land classes in relation to other classes both at ecological zone level. .

\section{RESULT AND DISCUSSION}

\subsection{Land Use Classification}

From the ALOS AVNIR-2 (Figure 3(a)), LU classification with seven classes was achieved. The distribution of these LU classes is presented in Figure 3(b) and their areal extent in Table 1. The LU classification was verified against the observations from every second ground spot. This accuracy assessment proved the classification to meet the international standards, at minimum $80 \%$ of pixels being classified correctly (GOFC-GOLD, 2011). As is clear from Table 1, Forest Land with closed canopy is $4,177.1 \mathrm{~km}^{2}$ and that with open canopy is $6,035.4 \mathrm{~km}^{2}$, covering altogether $10,212.5 \mathrm{~km}^{2}$ (that is, 67.4\%) of the study area. In the cropland major crops are cocoa, maize, banana with the cocoa plantation mainly in the lower half of the study area. Similarly, available wetlands are all lake, reservoir, or river and these can be also recognized as Water body.

\begin{tabular}{|l|r|r|}
\hline Land Use Class & Area (in $\mathbf{~ K m}^{\mathbf{2}}$ ) & Area (in \%) \\
\hline $\begin{array}{l}\text { Forest Land (Closed } \\
\text { canopy) }\end{array}$ & $4,177.1$ & 27.6 \\
\hline $\begin{array}{l}\text { Forest Land (Open } \\
\text { canopy) }\end{array}$ & $6,035.4$ & 39.8 \\
\hline Cropland & $3,006.2$ & 19.8 \\
\hline Grassland & $1,625.6$ & 10.7 \\
\hline Settlements & 268.3 & 1.8 \\
\hline Wetlands & 4.6 & 0.0 \\
\hline Other Land & 35.9 & 0.2 \\
\hline Total & $\mathbf{1 5 , 1 5 3 . 0}$ & $\mathbf{1 0 0 . 0}$ \\
\hline
\end{tabular}

Table 1: Area of Land Use Classes 


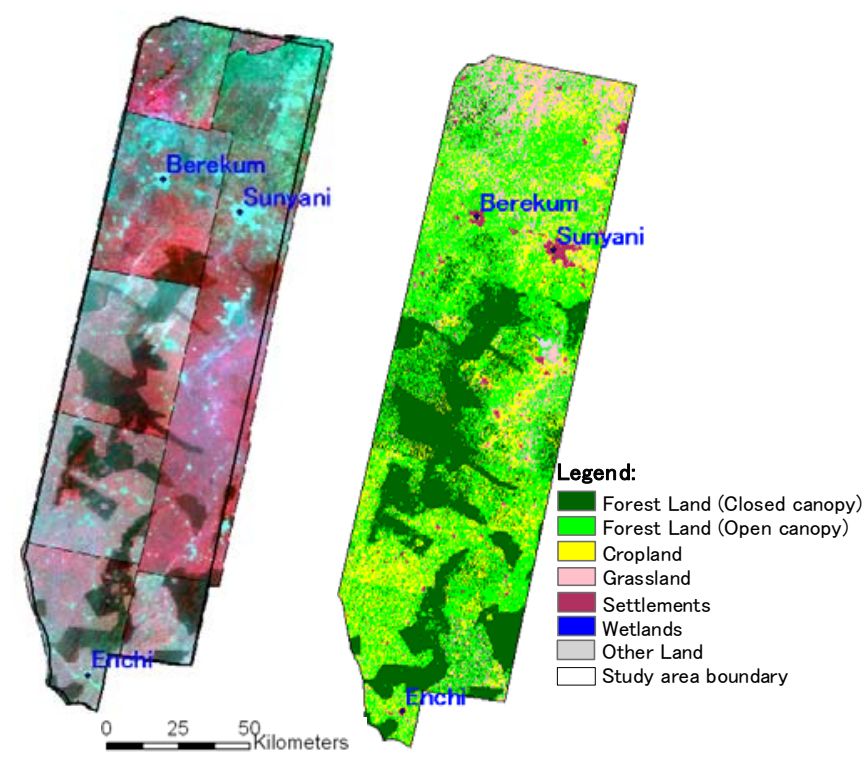

Figure 3 (a) Satellite Imagery (Bands 4, 3, 2 as R, G, B) and (b) result of Land Use Types Classification.

Figure 4 illustrates the distribution of LU categories over the study area. The proportion of the closed canopy forests is largest within ME (45.6\% of the area), MSD-NW (37.6\%), and MSD-SE (31.9\%) zones. In S, DSD-F and DSF-I zones the dominating LU/LC classes are grassland (49.8\%, 22.8\% and $10.5 \%)$, cropland $(15.5 \%, 31.5 \%$ and $40 \%$ ) open canopy forests (27.7\%, 43.8\% and $46.1 \%)$, respectively.

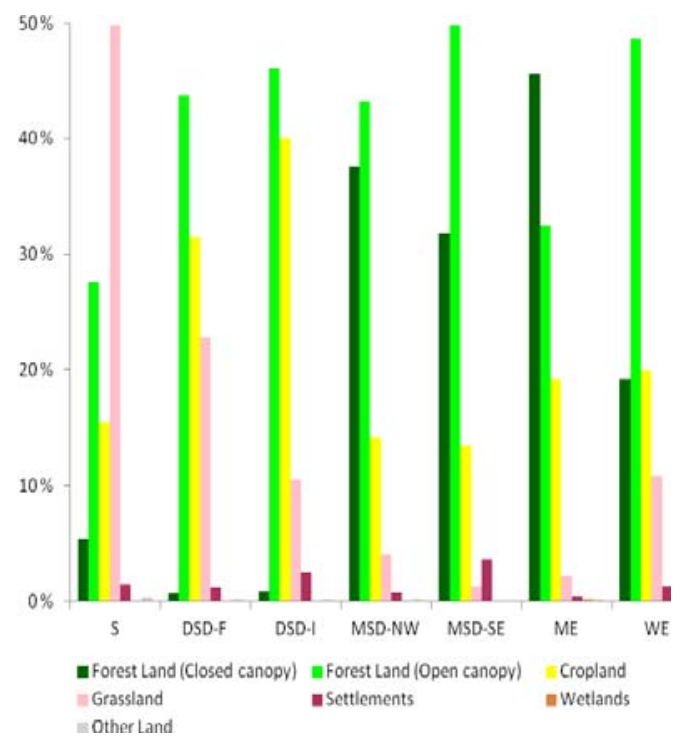

Figure 4. Land Use (LU) Classification Statistics over the Ecological Zones within the Study Area.

\subsection{LiDAR Sampling Strips}

Three systematic north-east - south-west strips were generated and the reference strip location was randomly sampled, as shown in Figure 5. These LiDAR strips, with $1 \mathrm{~km}$ width and additional 100m buffer, are to provide an unbiased sample of the broad ecological forest types existing within the study area.

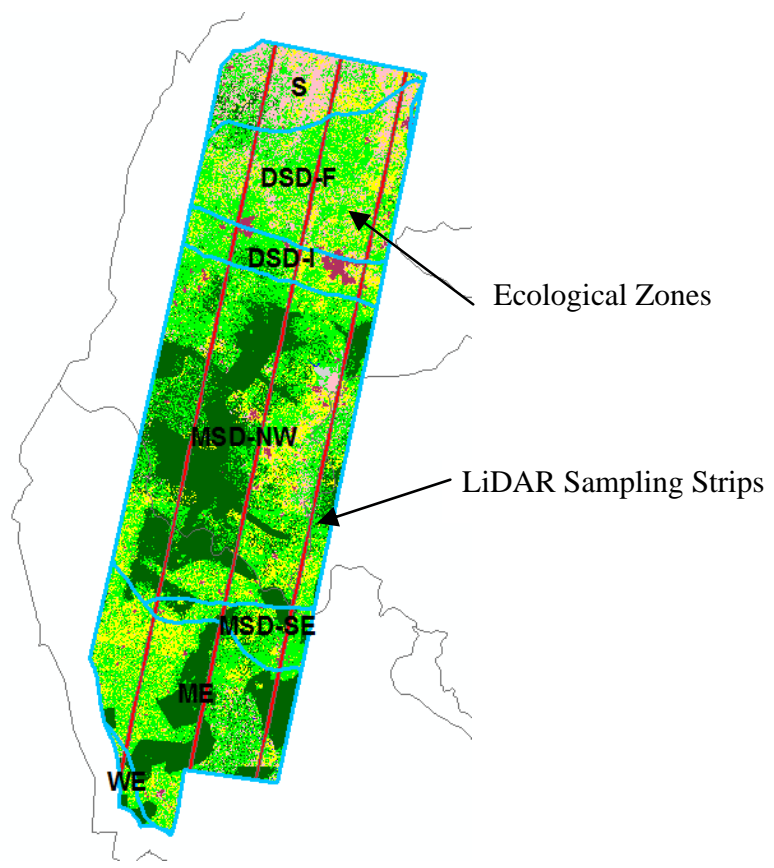

Figure 5. Systematic LiDAR Strip Sample.

The LiDAR scanning was conducted during December 2011. On average, a swath width of $644 \mathrm{~m}$ for each of the 3-4 parallel scanning transects were scanned to cover $1.1 \mathrm{~km}$ wide sample strips. More detailed metadata for LiDAR data is given in Table 2. The LiDAR point cloud data was processed and classified into default, ground and error classes. A sample processed data has been illustrated in Figure 6, which shows the scanned LiDAR sampling strips captured desired land use variability in the study area.

\begin{tabular}{|l|l|}
\hline Total Coverage & $770 \mathrm{~km}^{2}$ \\
\hline Aerial Platform & Fixed wing aircraft \\
\hline $\begin{array}{l}\text { Flying altitude, above-ground } \\
\text { level (AGL) }\end{array}$ & $1300 \mathrm{~m} /+-100 \mathrm{~m}$ \\
\hline Flying speed & 120 knots \\
\hline Sensor & Leica ALS50-II \\
\hline Sensor pulse rate & $81.100 \mathrm{kHz}$ \\
\hline Sensor scan speed outgoing pulse & $47.6 \mathrm{~Hz}$ \\
\hline $\begin{array}{l}\text { Nominal returns } / \mathrm{m}^{2} \\
\text { density, at ground level }\end{array}$ & 27 degrees \\
\hline Scan Field-of-View & $644 \mathrm{~m}$ \\
\hline Swath width, at ground level & $31 \mathrm{~cm} / \mathrm{e}^{2}$ \\
\hline Beam footprint, at ground level &
\end{tabular}

Table 2. Airborne LiDAR Scanning Parameters. 


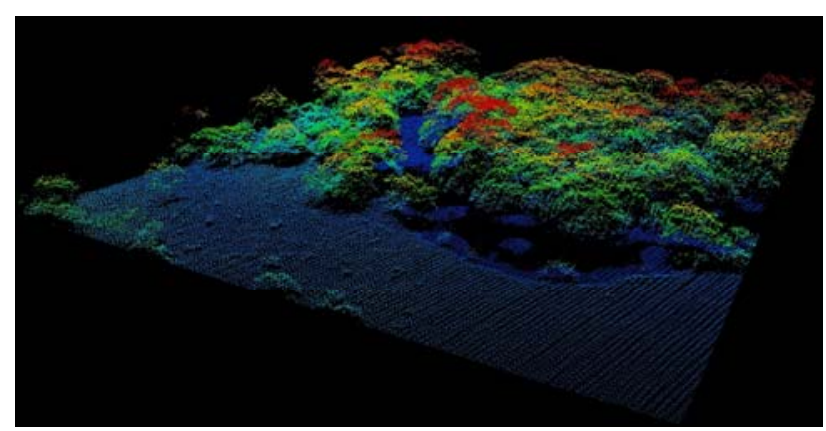

Figure 6. A Sample View of the Acquired LiDAR Data

Disregarding the ecological zones, the systematic LiDAR sample design captures different LU classes over the study area efficiently (Figure 7). The same applies to closed and open canopy forest classes when different ecological zones are studied independently (Figure 8). Within the DSD-I zone the sampling rate $(0.8 \%)$, for closed forests, remain remarkably below the average prevalence ratio of $4.9 \%$ for this zone. The Pearson's Chi-Squared test results indicate that the sample proportion of closed and open forests is significantly lower than expected at $95 \%$ confidence level in case of DSD-I and WE (Table 3).

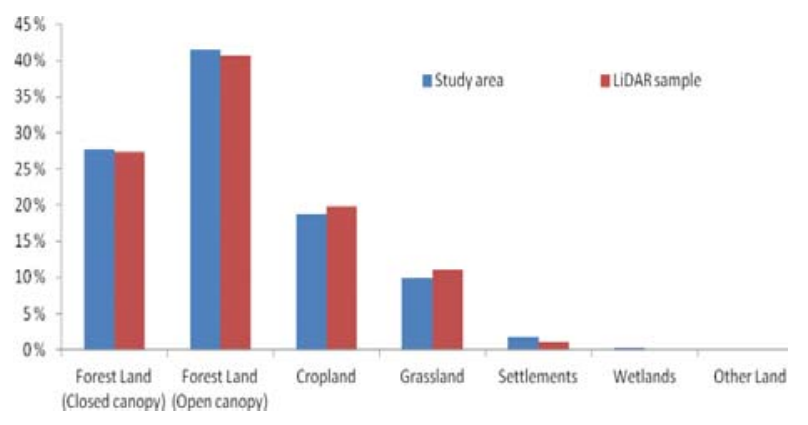

Figure 7. Land Use (LU) Class Proportions, Study Area vs. LiDAR Sample

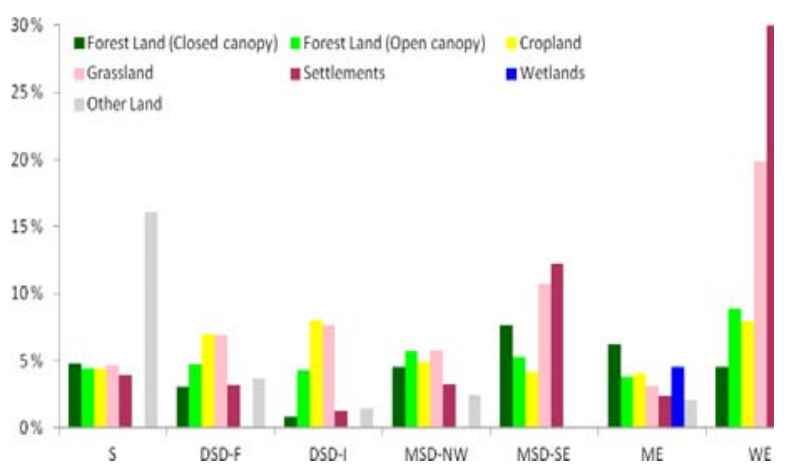

Figure 8. Proportional LiDAR Sampling Intensity per Land Use (LU) class.

\begin{tabular}{|c|c|c|}
\hline $\begin{array}{c}\text { Ecological } \\
\text { Zone }\end{array}$ & $\begin{array}{c}\text { Sample Area } \\
\left(\mathbf{k m}^{\mathbf{2}} \mathbf{)}\right.\end{array}$ & P-value \\
\hline S & 58.2 & 0.9831 \\
\hline DSD-F & 142.9 & 0.1876 \\
\hline DSD-I & 39.6 & 0.0210 \\
\hline MSD-NW & 344.6 & 0.5792 \\
\hline MSD-SE & 34.7 & 0.1972 \\
\hline ME & 140.1 & 0.0535 \\
\hline WE & 9.8 & 0.0103 \\
\hline
\end{tabular}

Table 3. The Pearson's Chi-squared Test Results to Assess the Sampling Representativeness of Two Forest Land Classes in Relation to other LU Classes.

\section{CONCLUSION}

The Land Use classification carried out in this study provided latest condition regarding the extent and distribution of LU classes as defined by IPCC with acceptable accuracy. The further stratification with the help of existing data of ecological zone resulted in more detailed classification and this remained very useful source of information for designing the LiDAR strip sample . It is important to validate the systematic strip sample design using recent LU classification especially in cases where the geographical area of strata is small or there is only a low proportion of forest land in relation to other LU classes.

The systematic LiDAR sampling design, presented in this paper, is likely to cover variation in above-ground biomass densities and serve as sufficient $a$-priori data together with the produced LU classification when designing efficient field plot sampling over the seven ecological zones. In that case, up to 50 field sample plots per ecological forest type are needed to train the regression models based on LiDAR pulse data derived metrics (Maltamo et al, 2010), once the above-ground biomass is the primary forest attribute to be estimated.

\section{REFERENCES}

Altrell D., Saket, M., Lyckebäck, L., and Piazza, M., 2007. National Forest Assessments - Country Projects Report "National Forest and Tree Resources Assessment 2005-2007 Bangladesh”, Rome, Italy. http://www.fao.org/forestry/17847/en/bgd/ (17 Sep. 2011).

Angelsen, A., Boucher, D., Brown, S., Merckx, V., Streck, C., and Zarin, D., 2011a. Modalities for REDD+ Reference Levels: Technical and Procedural Issues. Report Prepared for the Government of Norway. Meridian Institute, Washington DC, USA.

http://www.REDD-OAR.org (13 Sep. 2011).

Angelsen, A., Boucher, D., Brown, S., Merckx, V., Streck, C., and Zarin, D., 2011b. Guidelines for REDD+ Reference Levels: Principles and Recommendations. Report Prepared for the Government of Norway., Meridian Institute, Washington DC, USA.

http://www.REDD-OAR.org (13 Sep. 2011).

Bickel, K., Richards, G., Kohl, M., Rodrigues, R. L. V., and Stahl, G., 2006. 2006 IPCC Guidelines for National Greenhouse Gas Inventories, Volume 4: Agriculture, 
Forestry and Other Land Use "Consistent Representation of Lands”, Kanagawa, Japan.

http://www.ipcc-

nggip.iges.or.jp/public/2006gl/pdf/4_Volume4/V4_03_C h3_Representation.pdf (10 Oct. 2010).

FAO, 2010. Global Forest Resource Assessment 2010 Country Report Ghana.

Gautam, B., Tokola, T., Hamalainen, J., Gunia, M., Peuhkurinen, J., Parviainen, H., Leppanen, V., Kauranne, T., Havia, J., Norjamaki, I., and Sah, B.P., 2010. Integration of airborne LiDAR, satellite imagery, and field measurements using a two-phase sampling method for forest biomass estimation in tropical forests. Proceedings of the International Symposium on "Benefiting from Earth Observation", 4 - 6 October 2010, Kathmandu, Nepal.

Global Observation for Forest and Land Cover Dynamics (GOFC-GOLD), 2011. Reducing greenhouse gas emissions from deforestation and degradation in developing countries: a sourcebook of methods and procedures for monitoring, measuring and reporting, GOFC-GOLD Report version COP171.GOFC-GOLD Project Office, Natural Resources Canada, Alberta, Canada.

http://www.gofc-gold.unijena.de/redd (10 Dec. 2010).

GOG, 1992. Constitution of the Republic of Ghana. Gazetted notification dated May 15, 1992 of Government of Ghana (GOG), Accra, Ghana.

Hall, J. B. and Swaine, M. D., 1981. Distribution and ecology of vascular plants in a tropical rain forest: Forest vegetation in Ghana (Geobotany). Dr. W. Junk Publishers, The Hague, pp. 71-99.

Larson, A. M., 2011. Forest tenure reform in the age of climate change: Lessons for REDD+. Global Environmental Change, 21 (2), pp. 540-549.

Maltamo M., Bollandsås O. M., Næsset, E., Gobakken, T., and Packalén, P., 2011. Different plot selection strategies for field training data in ALS-assisted forest inventory. Forestry, 84(1), pp. 23-31.

MEST, 2002. National Biodiversity Strategy for Ghana. Ministry of Environment, Science \& Technology, (MEST), Accra, Ghana.

MLF, 1999. National Land Policy. Ministry of Lands and Forestry (MLF), Accra, Ghana.

MLF, 1994. Forest and Wildlife Policy. Ministry of Lands and Forestry (MLF), Accra, Ghana.

Nonomura, A., Hozumi, S., and Masuda, T., 2010. Rule-based Classification of ALOS/AVNIR-2 and PRISM data for Bamboo Distribution Mapping. The International Archives of the Photogrammetry, Remote Sensing and Spatial Information Science, Kyoto, Japan, vol. XXXVIII, Part 8, pp. 753-758.

http://www.isprs.org/proceedings/XXXVIII/part8/pdf/W08L21 _20100307175959.pdf (26 Sep. 2011).
Sah, B. P. Honji, K., Sah, A. K., Havia, Hamalainen, J., and Gautam, B., 2010. Mapping Land Cover Change and Forest Biomass using Satellite Imagery and Airborne LiDAR. Proceedings of the International Symposium on "Benefiting from Earth Observation”, 4 - 6 October 2010, Kathmandu, Nepal.

Soyama N., Muramatsu, K., Furumi S., and Daigo M., 2010. Development of Validation Data Sets for Global Land Cover Classification Using ALOS/AVNIR-2 Data, The International Archives of the Photogrammetry, Remote Sensing and Spatial Information Science, Kyoto, Japan, vol. XXXVIII, Part 8, pp. 937-940.

http://www.isprs.org/proceedings/XXXVIII/part8/pdf/W08P12_ 20100308235839.pdf (30 Sep. 2011).

\section{Acknowledgements}

The ongoing FPP project is funded by the Government of Japan. The project is implemented by Forestry Commission of Ghana. Most of the data used in this study has been provided by Forestry Commission of Ghana. The inputs and comments provided by Jussi Peuhkurinen, Olli Isotupa and Petri LatvaKäyrä of Oy Arbonaut Ltd and Nami Kubo of PASCO Corporation were useful to shape the paper in this form. We would also like to acknowledge the comments and suggestions provided by two anonymous reviewers. 